\title{
SISTEM PAKAR DIAGNOSA PENYAKIT PARU-PARU DENGAN METODE FORWARD CHAINING
}

\author{
Anugerah Jaya Aziz Amrullah 1, Ekojono \\ Program Studi Teknik Informatika, Jurusan Teknologi Informasi, Politeknik Negeri Malang \\ JL. Soekarno-Hatta No. 9 Malang 65141, Indonesia \\ 1. anugerahjaya93@gmail.com, ${ }^{2}$ ekojono@polinema.ac.id
}

\begin{abstract}
Abstrak
Paru-paru adalah organ yang berfungsi untuk menukar oksigen dengan karbondioksida di dalam darah yang prosesnya ini disebut respirasi atau pernafasan. Menurut kemenkes dr. Supriyantoro, Sp.P, MAR pada tahun 2013 ditemukan jumlah kasus penyakit paru-paru sebanyak 196.310 kasus, menurun bila dibandingkan kasus penyakit paru-paru yang ditemukan tahun 2012 yang sebesar 202.301 kasus. Penyakit paru-paru merupakan penyakit yang tidak mudah untuk di sembuhkan, dapat menjadi buruk apabila tidak segera ditangani dengan serius. Keterbatasan jumlah pakar atau ahli paru-paru tidak dapat mengatasi permasalahan para penderita penyakit paru-paru, makadari itu diperlukan sebuah sistem yang mana sistem tersebut dapat membantu kerja seorang pakar. Pada sistem pakar diagnosa penyakit paru-paru ini menggunakan metode forward chaining untuk pencarian fakta dan metode certainty factor untuk perhitungan tingkat kepercayaannya. Sistem pakar ini diimplementasikan dalam bentuk website, yang bertujuan untuk memudahkan para pengguna mencari informasi atau mendiagnosa penyakit paruparunya. Proses pengujian sistem pakar diagnosa penyakit paru-paru adalah dengan membandingkan perhitungan manual, perhitungan sistem, dan dari seorang pakar yang nantinya akan menghasilkan keakuratan sistem. Penelitian ini menghasilkan keakuratan diagnosa penyakit sebesar 86,66 \% dan error sebesar 13,34 \% dari 15x pengujian.
\end{abstract}

Kata kunci: Paru-paru, sistem pakar, forward chaining, certainty factor

\section{Pendahuluan}

Kesehatan merupakan hal yang penting bagi manusia. Ironisnya, banyak sekali penyakit-penyakit yang terlambat didiagnosis sehingga mencapai tahap kronis yang sulit untuk disembuhkan contohnya adalah penyakit paru-paru pada manusia. Paru-paru adalah organ yang berfungsi untuk menukar oksigen dengan karbondioksida di dalam darah yang prosesnya ini disebut respirasi atau pernafasan.

Menurut kemenkes dr. Supriyantoro, Sp.P, MAR pada tahun 2013 ditemukan jumlah kasus penyakit paru-paru sebanyak 196.310 kasus, menurun bila dibandingkan kasus penyakit paru-paru yang ditemukan tahun 2012 yang sebesar 202.301 kasus. Jumlah kasus tertinggi yang dilaporkan terdapat di provinsi dengan jumlah penduduk yang besar yaitu Jawa Barat, Jawa Timur, dan Jawa Tengah. Kasus penyakit paru-paru di tiga provinsi tersebut hampir sebesar $40 \%$ dari jumlah seluruh kasus baru di Indonesia. Dari jenis kelamin, penyakit paru-paru pada laki-laki lebih tinggi daripada perempuan yaitu hampir 1,5 kali dibandingkan penyakit paru-paru pada perempuan. Pada masingmasing provinsi di seluruh Indonesia kasus penyakit paru-paru lebih banyak terjadi pada laki-laki dibandingkan perempuan. Menurut kelompok umur, kasus baru yang ditemukan paling banyak pada kelompok umur 25-34 tahun yaitu sebesar 21,40\% diikuti kelompok umur 35-44 tahun sebesar 19,41\% dan pada kelompok umur 45-54 tahun sebesar $19,39 \%$.

Berdasarkan pemaparan di atas, penulis membuat sebuah aplikasi sistem pakar yang berfungsi memudahkan penderita penyakit paru-paru agar bisa mendiagnosa penyakitnya sejak awal dengan menggunakan metode forward chaining untuk pencarian fakta dan certainty factor untuk perhitungan tingkat kepercayaan.

\section{Sistem Pakar}

Secara umum, sistem pakar (expert system) adalah sistem yang berusaha mengadopsi pengetahuan manusia ke komputer, agar komputer dapat menyelesaikan masalah seperti yang biasa dilakukan oleh para ahli. Sistem pakar yang baik dirancang agar dapat menyelesaikan suatu permasalahan tertentu dengan meniru kerja dari para ahli. Dengan sistem pakar ini, orang awampun dapat menyelesaikan masalah yang cukup rumit yang sebenarnya hanya dapat diselesaikan dengan bantuan para ahli. Bagi para ahli, sistem pakar ini juga akan membantu aktivitasnya sebagai asisten yang sangat berpengalaman.

\section{Forward Chaining}

Forward chaining adalah teknik pencarian yang dimulai dengan fakta yang diketahui, kemudian mencocokkan fakta-fakta tersebut dengan bagian IF dari rules IF-THEN. Bila ada fakta yang cocok 
dengan bagian IF, maka rule tersebut dieksekusi. Bila sebuah rule dieksekusi, maka sebuah fakta baru (bagian THEN) ditambahkan kedalam database. Setiap kali pencocokan, dimulai dari rule teratas. Setiap rule hanya boleh dieksekusi satu saja. Proses pencocokan berhenti bila tidak ada lagi rule yang dieksekusi. Metode pencarian yang digunakan adalah Depth-First Search (DFS), Breadth-First Search (BFS) atau Best First Search.

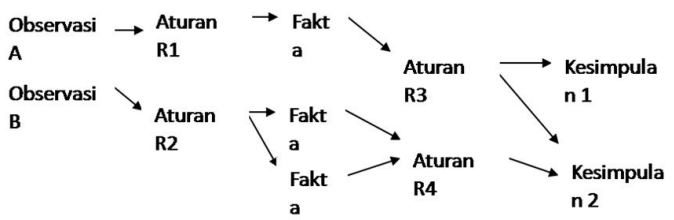

Gambar 1. Pelacakan Kedepan Forward Chaining.

\section{Certainty Factor}

Certainty factor merupakan salah satu teknik yang digunakan untuk menyatakan keyakinan fakta atau hipotesis. Oleh karena itu, CF digunakan untul emnunjukan seberapa akurat nilai keyakinan dan ketidakyakinan yang independen satu sama lain. CF dapat diekspresikan ke dalam sautau persamaan berikut :

$\mathrm{CF}(\mathrm{H}, \mathrm{E})=\mathrm{MB}(\mathrm{H}, \mathrm{E})-\mathrm{MD}(\mathrm{H}, \mathrm{E})$

$\mathrm{CF}$ hipotesis $\mathrm{H}$ atas munculnya evidence $\mathrm{E}$ dinotasikan dengan $\mathrm{CF}(\mathrm{H}, \mathrm{E})$ yang memiliki persamaan $\mathrm{MB}(\mathrm{H}, \mathrm{E})$ atau ujuran keyakinan terhadap hipotesis $\mathrm{H}$ atas munculnya evidence $\mathrm{E}$ dikurangi dengan $\mathrm{MD}(\mathrm{H}, \mathrm{E})$ sebagai ukuran ketidakyakinan terhadap hipotesis $\mathrm{H}$ atas munculnya evidence $\mathrm{E}$. selanjutnya diketahui rumus dasar CF untuk kaidah IF E THEN H sebagai berikut : :
$\mathrm{CF}(\mathrm{E}, \mathrm{e})=\mathrm{CF}(\mathrm{E}, \mathrm{e}) * \mathrm{CF}(\mathrm{H}, \mathrm{E})$

Dimana $\mathrm{CF}(\mathrm{H}, \mathrm{e})$ merupakan notasi $\mathrm{CF}$ yang didasarkan pada ketidakyakinan evidence e. $\mathrm{CF}(\mathrm{E}, \mathrm{e})$ merupakan $\mathrm{CF}$ dari kejadian $\mathrm{E}$ yang dipengaruhi evidence $\mathrm{e}$, dapat dinotasikan dengan persamaan berikut

$\mathrm{CF}(\mathrm{E}, \mathrm{e})=\min \left[\mathrm{CF}\left(\mathrm{e}_{1}\right), \mathrm{CF}\left(\mathrm{e}_{2}\right), \ldots, \mathrm{CF}\left(\mathrm{e}_{\mathrm{n}}\right)\right]$

Apabila gabungan estimasi menggunakan operator AND, atau

$\mathrm{CF}(\mathrm{E}, \mathrm{e})=\max \left[\mathrm{CF}\left(\mathrm{e}_{1}\right), \mathrm{CF}\left(\mathrm{e}_{2}\right), \ldots, \mathrm{CF}\left(\mathrm{e}_{\mathrm{n}}\right)\right]$

Apabila gabungan estimasi operator $\mathrm{OR} \mathrm{CF}(\mathrm{H}, \mathrm{E})$ adalah $\mathrm{CF}$ dalam hipotesis asumsi evidence diketahui dengan pasti yaitu ketika $\mathrm{CF}(\mathrm{E}, \mathrm{e})=1$. Apabila terdapat dua aturan yamg mempunyai kesimpulan hipotesis yang sama, maka $\mathrm{CF}$ gabungan dua aturan tersebut dihitung dengan kombinasi fungsi keyakinan dengan persamaan sebagai berikut

$$
\mathrm{CF}\left(\mathrm{CF}_{1}, \mathrm{CF}_{2}\right)=\left\{\begin{array}{c}
C F 1+C F 2(1-C F 1) \\
\frac{C F 1+C F 2}{1-\min [|C F 1|, \mid C F]} \\
C F 1+C F 2(1+C F 1)
\end{array}\right.
$$

\section{Akuisisi Pengetahan}

Dengan mewawancarai seorang pakar atau ahli paru-paru untuk memperoleh data secara jelas dan rinci sehingga mendapatkan data yang valid.

Tabel 5.1 Daftar Penyakit Paru-paru

\begin{tabular}{|r|r|r|c|c|c|c|c|c|c|c|c|}
\hline \multirow{2}{*}{ No } & \multirow{2}{*}{ Gejala } & \multicolumn{9}{|c|}{ Penyakit } \\
\hline & & P01 & P02 & P03 & P04 & P05 & P06 & P07 & P08 & P09 & P10 \\
\hline 1 & G01 & 0.9 & 0.9 & & & & & & 0.5 & & \\
\hline 2 & G02 & 0.9 & 0.8 & 0.3 & & & & & 0.7 & 0.5 & \\
\hline 3 & G03 & 0.5 & & 0.9 & & 0.9 & 0.9 & 0.9 & & 0.5 & 0.9 \\
\hline 4 & G04 & 0.3 & & 0.8 & & 0.8 & 0.8 & 0.8 & & 0.5 & 0.8 \\
\hline 5 & G05 & 0.3 & & 0.8 & & 0.8 & 0.8 & 0.8 & & 0.5 & 0.8 \\
\hline 6 & G06 & 0.3 & 0.5 & & 0.9 & & 0.5 & 0.5 & & 0.5 & \\
\hline 7 & G07 & & & & & & 0.9 & 0.9 & 0.5 & & 0.9 \\
\hline 8 & G08 & & 0.7 & & & & & & 0.5 & 0.9 & \\
\hline 9 & G09 & & 0.5 & & & & & & & & \\
\hline 10 & G10 & & & & & & 0.9 & & & & \\
\hline 11 & G11 & & 0.3 & & & & & & & & \\
\hline 12 & G12 & & 0.8 & & & & & & & & \\
\hline 13 & G13 & & 0.9 & & & & & & & & \\
\hline 14 & G14 & & & & & & & & 0.9 & & \\
\hline 15 & G15 & 0.9 & & & & & & & & & \\
\hline
\end{tabular}




\begin{tabular}{|r|r|l|l|l|l|l|l|l|l|l|l|}
\hline 16 & G16 & & & & 0.9 & & & & & \\
\hline 17 & G17 & & & & & & 0.9 & & & & \\
\hline 18 & G18 & & 0.5 & & 0.5 & & & & & \\
\hline 19 & G19 & & & & 0.9 & & & & & 0.9 & \\
\hline 20 & G20 & & & 0.9 & & & & & & \\
\hline 21 & G21 & 0.9 & & & & 0.9 & & & & & \\
\hline 22 & G22 & & & & & 0.5 & & & & \\
\hline 23 & G23 & & & & & 0.5 & & & & \\
\hline 24 & G24 & & & & & & & & 0.9 & \\
\hline 25 & G25 & & & 0.9 & & & & & 0.9 & \\
\hline 26 & G26 & & 0.9 & & & & & & & \\
\hline 27 & G27 & & & & 0.9 & & & & & \\
\hline 28 & G28 & & & & & 0.9 & 0.9 & & & \\
\hline 29 & G29 & & & & & & & 0.9 & & \\
\hline 30 & G30 & & & & & & & & 0.3 & \\
\hline
\end{tabular}

\section{Proses Identifikasi Hama dan Penyakit}

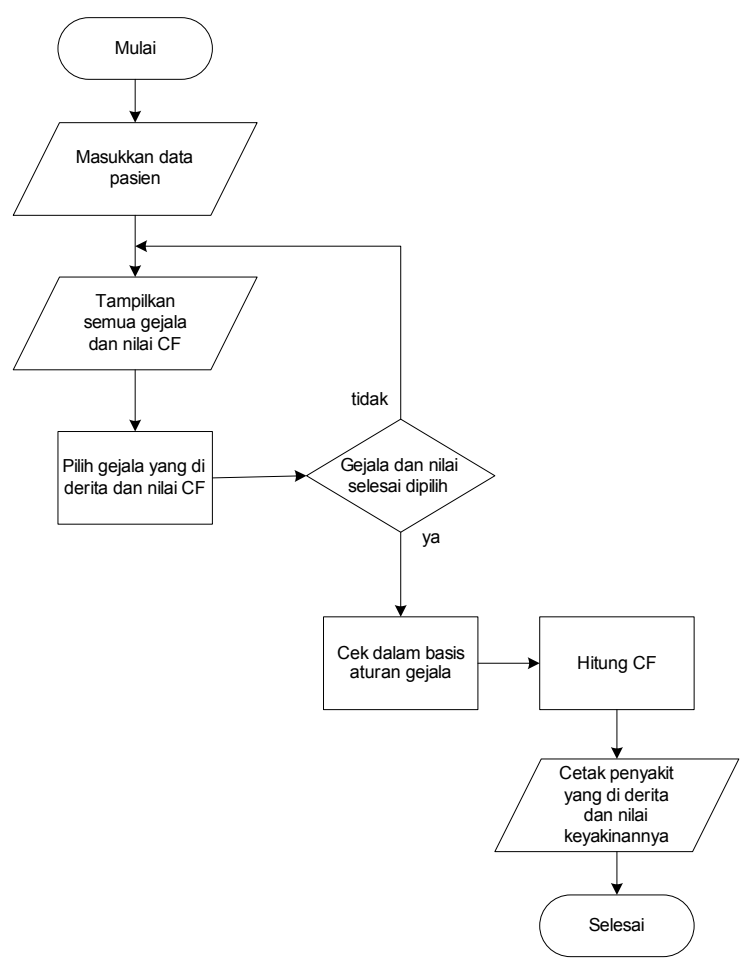

Gambar 2. Diagram alir konsultasi sistem pakar

Dari Gambar diatas dijelaskan proses diagnosa sistem pakar penyakit paru-paru. Dimulai dari memasukkan data pasien dilanjutkan dengan menampilkan semua gejala dan nilai certainty factornya, kemudian pasien memilih gejala dan nilai certainty factornya sesudah memilih, gejala yang sudah di pilih tadi akan di cocokkan dengan basis aturan kemudian akan di lanjutkan dengan menghitung dengan metode certainty factor dan akan mengeluarkan hasil penyakit yang di derita pasien dan nilai keyakinannya.

7. Tampilan Antar muka 7.1 Tampilan Pengguna

Sistem Pakar

Diganosa Penyakit Paru-paru

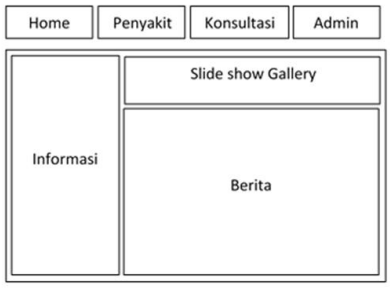

Gambar 3. Tampilan halaman utama user

\subsection{Tampilan Admin}

\section{Sistem Pakar}

Diganosa Penyakit Paru-paru

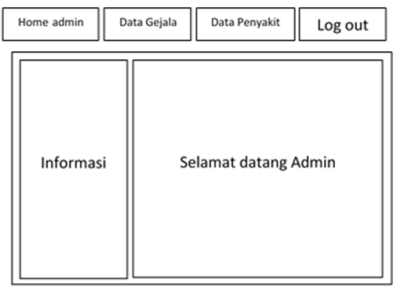

Gambar 4. Tampilan halaman utama admin

\section{Perancangan Perangkat Lunak \\ 8.1 ERD}

Entity Relational Diagram (ERD) adalah model yang menerangkan hubungan data pada sebuah basis data. Hubungan antar data tersebut di hubungkan dengan sebuah relasi. Data - data tersebut gambarkan dengan entitas yang mempunyai atribut. 
Atribut tersebut berfungsi untuk mendeskripsikan dan memaparkan sifat dari entitas tersebut.

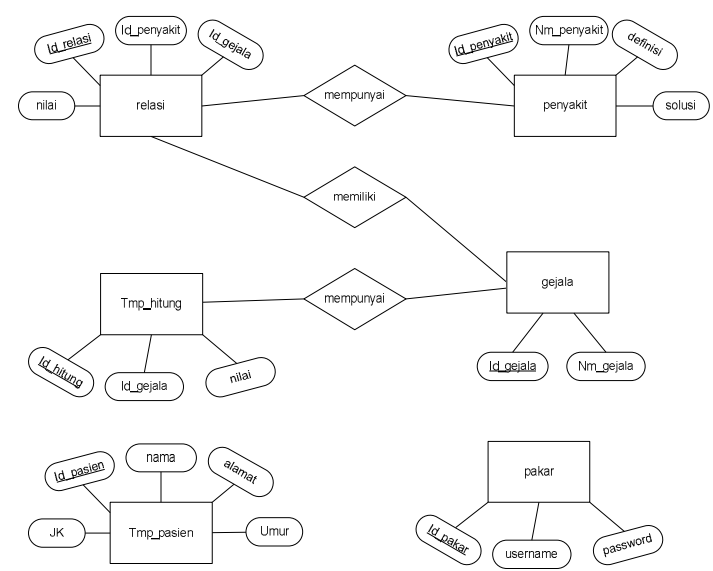

Gambar 5. ERD sistem pakar

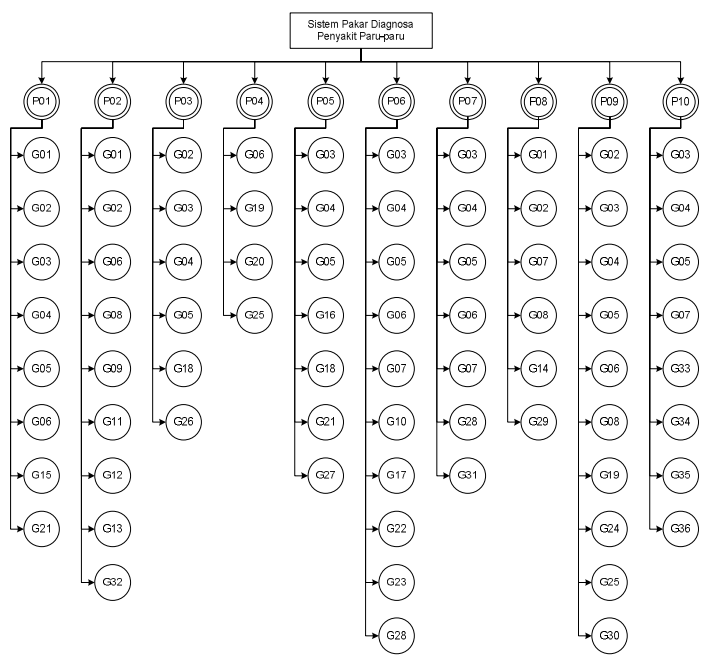

Gambar 6. Pohon keputusan.

\section{Pembahasan}

Ketepatan hasil analisis sistem diuji dengan melakukan penilaian terhadap output sistem berdasarkan input yang diberikan user, yaitu apakah output yang dihasilkan sudah tepat apabila dinilai dari sudut pandang seorang pakar.

Sebagai contoh untuk perhitungan pada penyakit Tuberkulosis yang terdapat pohon keputusan sebagaimana tampak pada penjelasan dibawah.

1. Input gejala yang dialami

- $\quad$ Nafsu makan menurun = iya $(0.9 * 1=0.9)$

- Berat badan menurun derastis = mungkin $(0.9 * 0.6=0.54)$

- Berkeringat dingin dimalam hari = iya $(0.9 * 1=0.9)$

- $\quad$ Batuk kronis = iya $(0.9 * 1=0.9)$
2. Cek aturan atau basis pengetahuan yang sesuai dengan gejala

Hitung nilai kepercayaannya

- $\mathrm{CF}_{\text {pakar }}($ Nafsu makan menurun $)=0,9$

- $\mathrm{CF}_{\text {pakar }}($ Berat bdan menurun derastis $)=0,9$

- $\mathrm{CF}_{\text {pakar }}$ (Berkeringat dingin dimalan hari) $=0.9$

- $\mathrm{CF}_{\text {pakar }}$ (Batuk kronis $)=0.9$

3. Selanjutnya dihitung CFpakar dengan CFuser menggunakan persamaan

- $\mathrm{CF}(\mathrm{H}, \mathrm{E})=\mathrm{CF}($ user $) * \mathrm{CF}($ pakar $)$

- $\mathrm{CF} 1.1=0.9 * 1=0.9$

- $\mathrm{CF} 1.2=0.9 * 0.6=0.54$

- $\mathrm{CF} 1.3=0.9 * 1=0.9$

- $\mathrm{CF} 1.4=0.9 * 1=0.9$

Langkah terakhir adalah mengkombinasikan nilai CF masing-masing rule :

$\mathrm{CF}_{\text {COMBINE }}(\mathrm{CF} 1, \mathrm{CF} 2)=\mathrm{CF} 1+\mathrm{CF} 2 *(1-\mathrm{CF} 1)$

sehingga menjadi

$\mathrm{CF}_{\text {COMBINE }}\left(\mathrm{CF}_{1.1}, \mathrm{CF}_{1.2}\right)=0.9+0.54 *(1-0.9)$

$=0.9+0.054=0.954 \mathrm{CF}_{\text {old }}$

Kombinasikan $\mathrm{CF}_{\text {old }}$ dan $\mathrm{CF} 1.3$

$\mathrm{CF}_{\text {COMBINE }}\left(\mathrm{CF}_{\text {old }}, \mathrm{CF}_{1.3}\right)=0.954+0.9 *(1-$

$0.954)=0.954+0.0414=0.9954 \mathrm{CF}_{\text {old }}$

Kombinasikan $\mathrm{CF}_{\text {old }}$ dan $\mathrm{CF} 1.4$

$\mathrm{CF}_{\text {COMBINE }}\left(\mathrm{CF}_{\text {old }}, \mathrm{CF}_{1.4}\right)=0.9954+0.9 *(1-$

$0.9954)=0.9954+0.00414=0.99954 \mathrm{CF}_{\text {old }}$

Prosentase keyakinan $=\mathrm{CF}_{\text {COMBINE }} * 100 \%=$ $0.99954 * 100 \%=99 \%$

Dengan demikian dapat disimpulkan bahwa perhitungan certainty factor yang dilakukan pada jenis Penyakit Tuberkulosis memiliki tingkat keyakinan sistem 99\%.

\section{Kesimpulan dan Saran}

\subsection{Kesimpulan}

Berdasarkan perancangan, implementasi dan uji coba sistem pakar diagnosa penyakit paru-paru, maka didapatkan kesimpulan sebagai berikut :

1. Berdasarkan tabel pengujian akurasi dapat di simpulkan bahwa sistem pakar diagnosa penyakit paru-paru menggunakan metode forward chaining untuk perunutan dan certainty factor untuk nilai kepercayaannya dapat mengidentifikasi penyakit dengan cukup baik. Hal ini dibuktikan dengan hasil pengujian akurasi sistem sebesar $86.66 \%$ dan error sebesar 13,34 \%. Nilai error tersebut dikarenakan hasil dari 
perhitungan sama besar dengan hasil kemungkinan penyakit lainnya.

2. Sistem pakar diagnosa penyakit paru-paru yang dibangun dapat memberikan kesimpulan identifikasi sesuai dengan pemikiran seorang pakar.

\subsection{Saran}

Berdasarkan penelitian ini, ada beberapa hal yang disarankan yaitu:

1. Diharapkan sistem ini dapat dikembangkan untuk penyakit selain paru-paru.

2. Aplikasi sistem pakar yang dibangun bisa dikembangkan menggunakan metode lain.

3. Parameter yang digunakan untuk menegakkan diagnosa pada sistem bisa menggunakan parameter selain yang digunakan pada sistem ini.

\section{Daftar Pustaka:}

Danusantoso, Halim., 2014., Buku Saku Ilmu Penyakit Paru., Jakarta., EGC

Hartati, Sri dan Sari Iswanti., 2013., Sistem Pakar dan Pengembangannya., Yogyakarta., Graha Ilmu.

Kementrian Kesehatan Republik Indonesia., 2014., Profil Kesehatan Indonesia Tahun 2013., Jakarta., Kementrian Kesehatan Republik Indonesia.

Dardanela, Sintia., 2014., Analisa dan perancangan sistem pakar penentuan penyakit kucing menggunakan metode forward chaining berbasis web., Jurnal Teknologi Informatika Politeknik Negeri Malang.

Putra, Firmansyah., 2011., Perancangan Sistem Pakar Identifikasi Penyakit Paru-paru Menggunakan Metode Forward Chaining., Jurnal Fakultas Sains dan Teknologi Universitas Islam Negeri Syarif Hidayatullah Jakarta.

Rini W, Benedicta dkk., 2012., Kecerdasan Buatan., Yogyakarta., ANDI.

Saputra, Andri., 2011., "Sistem Pakar Identifikasi Penyakit Paru-Paru Pada Manusia Menggunakan Pemrograman Visual Basic 6.0”., Jurnal Fakultas Teknologi dan Informatika STIMIK PalCom Tech Palembang.

Sommerville, Ian., 1992., Software Engineering., United States of America., Addison-Wesley.

Muhlisin, Ahmad., 2015., Pneumonia-Pengertian, Gejala, Penyebab, dan Pengobatan., http://mediskus.com/penyakit/pneumonia.html Diakses pada 28 Januari 2015.

Yolanda, Natharina., 2014., Efusi Pleura., http://www.kerjanya.net/faq/5407-efusi-

pleura.html\#efusi-pleura-adalah Diakses pada 28 Januari 2015. 